\title{
Transcription Initiation Factor TFIID Subunit 4
}

National Cancer Institute

\section{Source}

National Cancer Institute. Transcription Initiation Factor T FIID Subunit 4. NCI Thesaurus.

Code C30065.

Transcription initiation factor TFIID subunit 4 (1085 aa, $110 \mathrm{kDa}$ ) is encoded by the human TAF4 gene. This protein is involved in the modulation of transcription. 